\title{
Original Article (short paper) \\ Effect of judo practice on the body composition of children and adolescents: A 9 month intervention
}

\author{
Diego de Souza Miranda ${ }^{1}$, Bruna Thamyres Ciccotti Saraiva ${ }^{1, *}$, Vinícius Yukio Botelho Suetake ${ }^{1}$, Davi da Silva \\ Alves $^{1}$, Daniel Eduardo Rodrigues de Sousa ${ }^{1}$, Ismael Forte Freitas Júnior ${ }^{1}$, Diego Giulliano Destro Christofaro ${ }^{1}$ \\ ${ }^{1}$ Universidade Estadual Paulista, UNESP, Presidente Prudente, SP, Brazil
}

\begin{abstract}
Aims: To analyze the effects of 9 months of judo training on the body composition of children and adolescents. Methods: 105 children and adolescents aged between 5 and 15 years were divided into two groups: control $(n=40)$ and Judo $(n=65)$, all participants of one Philanthropic institution. Anthropometric measurements, total body composition, and body composition per region were performed using DEXA. The judo intervention lasted 9 months, held twice a week for one hour. The control group did not perform any type of training. Repeated measures ANOVA with adjustments for age, sex, and maturation, and the effect size by Eta Squared were performed. SPSS software version 13.0 was used and the statistical significance adopted was p-value $<5 \%$. Results: After the intervention, statistical significance was observed in body fat $(\mathrm{kg})(\mathrm{p}$-value=0.031). There was an increase in BF in both groups; however this increase was much higher in the control group. Conclusion: The practice of 9 months of judo was effective for the maintenance of body fat in children and adolescents.
\end{abstract}

Keywords: martial arts, children, adolescents, physical activity, judo.

\section{Introduction}

Obesity is characterized by excessive accumulation of body fat and obesity in childhood and adolescence is strongly linked to obesity in adult life $\mathrm{e}^{1,2}$. Both obesity and gaining excessive weight are related to several noncommunicable diseases. These diseases are usually associated with high mortality rates, such as diabetes, hypertension, and stroke, among others ${ }^{3}$. Thus, behavioral changes are necessary, especially in the pediatric population. Therefore, the practice of physical activity may play an important role in health, since it is able to reduce body fat and lead to better physical fitness conditions ${ }^{4}$.

Periodic exercise is recommended for the pediatric population by the American College of Sports Medicine ${ }^{5}$, since the characteristics of periodic exercise resemble the population's daily life and routine. In this sense, martial arts, such as judo (which is a dynamic and intermittent exercise), can be employed. It must also be noted that judo is a sport in which body weight must be supported, and falls often occur; subjecting the body to constant ground reaction forces. Thus, these characteristics are often considered to be responsible for increases in the skeletal structure, which in turn provides some health benefits ${ }^{6,7}$.

In addition to being a combat sport, judo presents itself as a means for acquiring a physical state which contemplates body composition, and can thus be effective in combating disorders through its practice in childhood and adolescence ${ }^{7,8}$. The majority of studies involving contact sports and young participants have investigated the effect of this practice on young athletes or children and adolescents with previous training $8,9,10,11$.

In this sense, few studies have had the objective of verifying the effectiveness of judo on the body composition of children and adolescents without previous experience in this modality. Our hypothesis was that judo could provide benefits to the body composition of children and adolescents submitted to this type of training, even without previous experience. Moreover, to verify such relations, confounding factors such as sex, age, and somatic maturation were used as control variables.

Therefore, to investigate the effects of Judo on a population without previous training meant implementing a training program for individuals without any prior involvement with judo. The objective of the present study was to analyze the effectiveness of nine months of judo practice on the body composition of children and adolescents.

\section{Methods}

\section{Participants}

The present study was longitudinally designed, with a duration of nine months, activities started in the first semester (June) of 2016, in the city of Presidente Prudente, São Paulo which has approximately 223,749 thousand inhabitants, a Human Development Index (HDI) of 0.806 according to data from the Brazilian Institute of Geography and Statistics (IBGE) (2010), and is located in southeastern Brazil. This research project was developed in partnership with a Philanthropic Institution that provides various activities for young people in need (chess, computers, different sports, etc). The institution from which the sample was taken serves between 200 and 250 participants per year and is located in a neighborhood near the center of the city, serving the children of several neighborhoods close to 
their location. Terms of the inclusion criteria for participants stated that the children and adolescents should: (i) be properly enrolled and participate in the activities of that institution; (ii) not present any type of illness that would make it impossible to carry out fighting activities; (iii) not be in the process of gestation; (iv) not be taking medications to control blood pressure or heart rate; and (v) return the Informed Consent Form duly signed by parents and/or guardians, authorizing the adolescent to participate in the project. The present study was approved by the Ethics and Research Committee of the State University of São Paulo (CAAE: 26702414.0.0000.5402, Ethics Committee Number: 549.549).

\section{Calculation of Sample Size}

The calculation of the sample size required for the study was performed by means of an equation for the comparison of two independent means (control group and practice of fights). A sample size of 64 young people (minimum of 32 in each group) was calculated to detect a reduction in body mass index of 2.6 $\mathrm{kg} / \mathrm{m}^{2}$ and a standard deviation of $2.9 \mathrm{~kg} / \mathrm{m}^{2}$ based on the study of $\mathrm{Hui}^{12}$. Statistical significance was $5 \%$ and power $80 \%$. With an increase of $20 \%$ for losses, the sample size required to start the intervention was at least 77 .

\section{Outcomes analyzed}

\section{Anthropometry}

Body mass was measured using a digital scale of the Plenna brand with an accuracy of $0.1 \mathrm{~kg}$. Height was evaluated through a portable stadiometer with a maximum extension of two meters and a precision of $0.1 \mathrm{~cm}$. After taking these two measures, the body mass index (BMI) was calculated by dividing body mass by the square of height. The height of the trunk was also measured by the same stadiometer, but with the individual sitting on a 50 $\mathrm{cm}$ bench, in order to calculate the Maturity Offset and age at peak height velocity (APHV). All evaluations were carried out by trained evaluators and according to the standardization of Freitas $\mathrm{Jr}^{13}$. These evaluations were performed before the start of the project and at the end.

\section{Somatic Maturation}

In order to measure the biological maturation of children and adolescents, the Maturity Offset prediction equation was used, for which there is a different formula for the female and male sex as proposed by Mirwald ${ }^{14}$. The formula represents the years that are missing (negative) or that have passed (positive) for the individual to reach his/her peak height. In this formula, the sex, age, height, weight, trunk height, and leg length (standing height less trunk height) are considered. The APHV was calculated by subtracting Maturity Offset from age. This variable was used as part of the adjustments within the analyses.

\section{Body Composition}

A Dual Energy X-Ray Absorptiometry (DEXA) scanner from General Electric (Lunar DPX-NT, General Electric Healthcare, Little Chalfont, Buckinghamshire, UK) was used to evaluate muscle mass, bone mineral content and bone mineral density (Lunar brand software, Version 4.7, GE Medical Systems, Madison, WI). The scanner quality was tested by a trained researcher prior to each day of measurement, following the manufacturer's recommendations. During the evaluation, participants wore light clothing, without any footwear, or any metal in or on the body, remaining in the dorsal position for approximately 15 minutes (time to perform the scan). Fat free mass $(\mathrm{kg})$ and fat mass $(\mathrm{kg})$ were evaluated, both total and by regions such as arms, legs, trunk, android, and gynoid. The precision of the machine in terms of coefficient of variation was $0.66 \%$ ( $n=30$ subjects not involved in this study) and all scans were carried out in a temperature-controlled laboratory at the university. In order to verify possible changes in body composition, these evaluations were also performed before the start and at the end of the project.

\section{Judo Practice Group and Control Group}

The intervention group consisted of 65 young people (who practiced judo for nine months). These young people participated in the practice of fights on floor space made available (already containing mats) by the Philanthropic Institution. The classes of different difficulties were offered at times that the adolescents would already be participating in the project, avoiding clashes with school class schedules, and possible transport costs, as the Institution develops projects with young people who live in the Neighborhood where it is located. All the young people were evaluated before the beginning and at the end of nine months, when this intervention was concluded.

Following the guidelines of the American College of Sports Medicine ${ }^{15}$ activities were carried out twice a week, (approximately 60 minutes duration) by practicing judo through activities and games involving movements typical of this modality ${ }^{16}$. During the classes, initiation activities were set to practice judo involving opposition games, speed games, conquests of objects, imbalance and also with specific movements (as recommended by the literature in this area) ${ }^{17,18}$. In the specific part of the modality, fall damping movements (ukemi-waza), immobilization techniques (hon-kesa-gatame and tate-shihogatame), and projection were practiced (o-soto-gari, o-goshi, ashi-guruma, koshi-guruma, tai-otoshi, and others). , Fight simulation (randori) was performed by the students in pairs, utilizing the technical skills learned in practice.

These activities had a moderate to high intensity setting and were evaluated through the Borg's scale ${ }^{19}$ adapted by Foster ${ }^{20}$, according to the participants' subjective perception of effort. At the end of each training session, the participants were asked to report the intensity of effort of the class, by means of the Borg scale, and students were requested to maintain the intensity at moderate to high. The intensity was measured by this scale as the use of a heart rate monitor is not recommended in contact sports, 
as it could provide abrasions. Class attendance was considered as a form of adjustment, and for the training to be effective a minimum class attendance of $75 \%$ was recommended, however, regardless of this percentage, all young people reassessed were included in the analyzes. The control group was composed of 40 young people who did not participate in the physical activities developed at the institution, but who participated in other activities offered (computer science, chess, art education classes) and also had the desire to be included in the evaluations of the health parameters offered in this project.

\section{Statistical Analysis}

Statistical analysis was performed using the Shapiro-Wilks normality test and the Student's independent t-test, to compare the pre-intervention moment of the two groups that characterized the sample (control and training). The delta was calculated and the Levene's test was performed to verify the homogeneity of the variances. Analysis of covariance (ANCOVA) was used to verify the differences between groups adjusted for sex, Maturity Offset, and presence in training class. Eta Squared effect size was calculated. SPSS software version 13.0 was used for all analysis and the level of significance was set at $5 \%$.

\section{Results}

The study consisted of 105 children and adolescents in two groups: the Judo group had 65 participants, 38 boys $(58.5 \%)$ and 27 girls $(41.5 \%)$, and the Control group had 40 children and adolescents, 30 boys (75\%) and 10 girls (25\%)(Figure 1).

Figure 1. Flow chart of the sample.

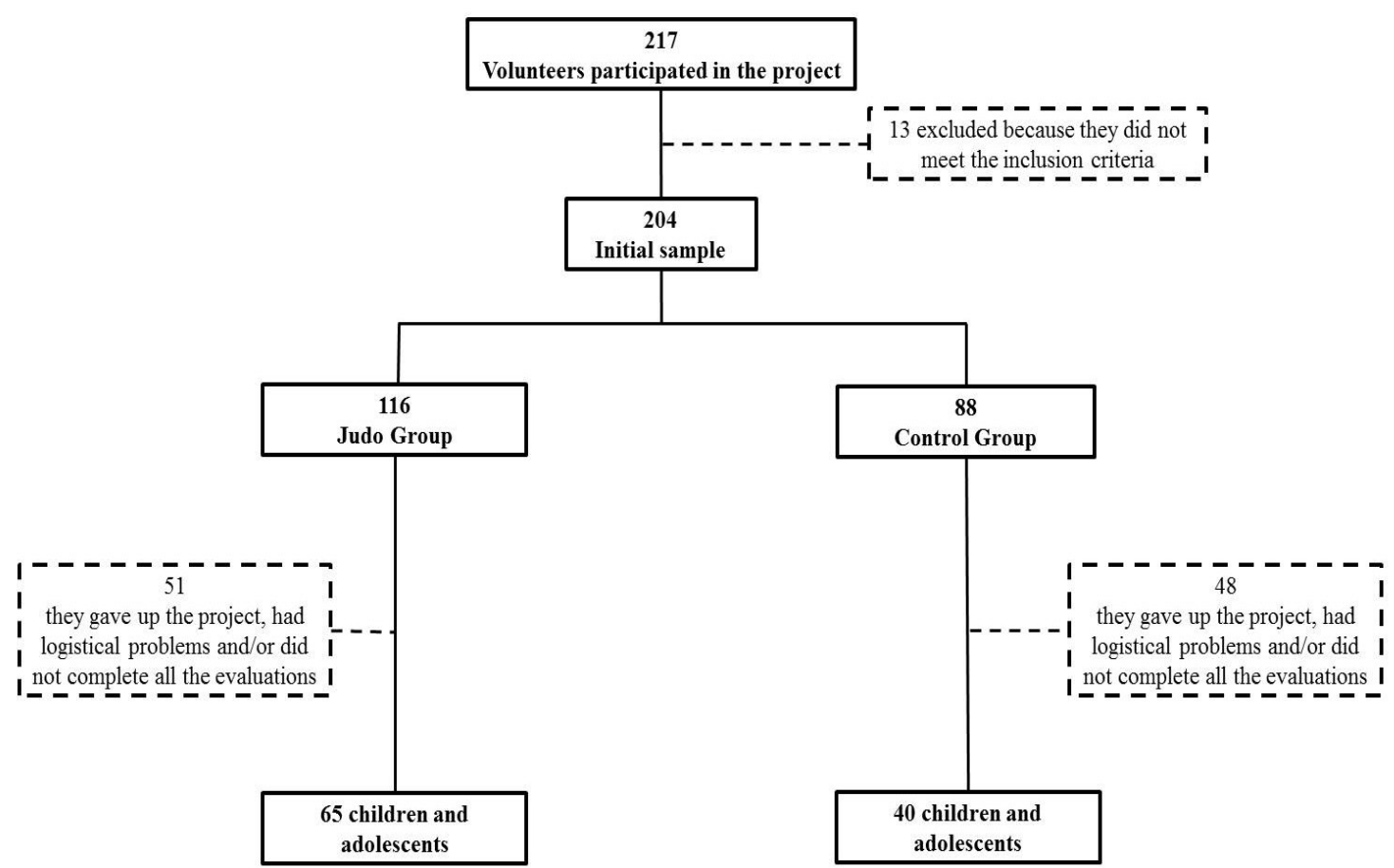

Table 1 presents the characterization of the sample at baseline. No significant difference ( $p$-value $>0.05$ ) was found between the groups at baseline in any of the variables included in the study.

The values of the judo training effect on body composition are presented in Table 2 . There was a difference between the groups for body fat $(\mathrm{kg})(\mathrm{p}$-value=0.031).

\section{Discussion}

The objective of the present study was to analyze the effects of 9-months of judo practice on the body composition of children and adolescents. Thus, according to the results obtained, both groups demonstrated an increase in body fatness $(\mathrm{kg})$, however, according to the deltas, for increase in adiposity, low values were observed in the control group when compared to the Judo group. Therefore, judo contributed to the maintenance of body fat in children and adolescents who underwent training.

Studies such as that of Franchini ${ }^{21}$ emphasize that Judo has predominantly anaerobic characteristics during the fights, however to sustain the small pause periods between fights requires use of the aerobic metabolism, acting both on lipid and protein metabolism ${ }^{21}$. Thus, the present study supports the evidence, as observed in the deltas, despite having obtained statistical significance only in body fat in kilograms, with low effect size. Tsang ${ }^{22}$, in a controlled clinical trial using a placebo (Tai Chi) activity in overweight/obese adolescents, observed that Kung Fu was able to reduce the expected gain in body fat for the whole body as well as for abdominal fat, but Tsang ${ }^{22}$ did not verify whether these changes were independent of sex, age, and somatic maturation of the young people. 
Table 1. Description of the sample.

\begin{tabular}{|c|c|c|c|}
\hline & $\begin{array}{c}\text { Judo }(\mathrm{n}=65) \\
\text { Mean (SD) }\end{array}$ & $\begin{array}{c}\text { Control }(n=40) \\
\text { Mean (SD) }\end{array}$ & $p$-value \\
\hline Age (years) & $9.57(2.03)$ & $9.83(2.93)$ & 0.600 \\
\hline BM Balance (kg) & $42.54(14.64)$ & $41.11(15.74)$ & 0.636 \\
\hline Stature $(\mathrm{cm})$ & $144.34(12.86)$ & $141.19(17.41)$ & 0.286 \\
\hline BMI $\left(\mathrm{kg} / \mathrm{m}^{2}\right)$ & $19.93(4.77)$ & $19.90(4.57)$ & 0.975 \\
\hline Maturity Offset (years) & $-4.21(1.21)$ & $-4.20(1.63)$ & 0.975 \\
\hline APHV (years) & $13.78(0.97)$ & $14.02(1.38)$ & 0.288 \\
\hline BM DEXA (kg) & $41.19(14.42)$ & $41.00(16.88)$ & 0.951 \\
\hline $\mathrm{BF}(\%)$ & $27.36(12.52)$ & $24.87(12.29)$ & 0.319 \\
\hline $\mathrm{BF}(\mathrm{kg})$ & $12.62(9.44)$ & $11.25(9.16)$ & 0.467 \\
\hline FFM Total (kg) & $27.06(6.80)$ & $26.99(8.04)$ & 0.964 \\
\hline FFM of Arms (kg) & $2.73(0.92)$ & $2.73(1.05)$ & 0.998 \\
\hline FFM of Legs (kg) & $9.59(2.74)$ & $9.35(3.46)$ & 0.685 \\
\hline FM of Arms (kg) & $0.84(0.74)$ & $0.73(0.74)$ & 0.486 \\
\hline FM of Legs (kg) & $5.21(3.68)$ & $4.72(3.56)$ & 0.503 \\
\hline Fat of Trunk (\%) & $29.13(14.01)$ & $26.61(13.87)$ & 0.369 \\
\hline BF Android (\%) & $30.62(16.68)$ & $28.31(15.89)$ & 0.481 \\
\hline BF Gynoid (\%) & $38.37(11.76)$ & $35.75(11.83)$ & 0.268 \\
\hline
\end{tabular}

$\mathrm{SD}=$ standard deviation; $\mathrm{BMI}=$ body mass index; $\mathrm{APHV}=$ age at peak height velocity; $\mathrm{BM}=$ body mass; $\mathrm{DEXA}=$ dual energy $\mathrm{x}$-ray absorptiometry; $\mathrm{BF}=$ body fat; FFM= fat free mass; FM= fat mass.

Table 2.Effect of Judo intervention on body composition in children and adolescents.

\begin{tabular}{|c|c|c|c|c|c|c|}
\hline & $\begin{array}{c}\text { Judo }(\mathrm{n}=65) \\
\Delta \operatorname{Mean}^{\mathrm{a}}(\mathrm{CI} 95 \%)\end{array}$ & $\begin{array}{c}\text { Control }(n=40) \\
\Delta \operatorname{Mean}^{\mathrm{a}}(\mathrm{CI} 95 \%)\end{array}$ & Levene's & $\mathbf{F}$ & $p$-value & ES \\
\hline BM DEXA (kg) & 2.63 (1.18 to 4.07$)$ & $2.16(0.27$ to 4.05$)$ & 0.138 & 0.140 & 0.709 & 0.001 \\
\hline $\mathrm{BF}(\%)$ & $-1.06(-1.99$ to -0.13$)$ & $-0.02(-1.23$ to 1.18$)$ & 0.801 & 1.683 & 0.197 & 0.017 \\
\hline $\mathrm{BF}(\mathrm{kg})$ & $0.15(-0.48$ to 0.80$)$ & $1.36(0.53$ to 2.19$)$ & 0.229 & 4.779 & 0.031 & 0.046 \\
\hline FFM Total (kg) & $2.62(2.16$ to 3.08$)$ & $2.39(1.79$ to 2.99$)$ & 0.204 & 0.328 & 0.568 & 0.003 \\
\hline FFM of Arms (kg) & $0.31(0.25$ to 0.37$)$ & $0.29(0.21$ to 0.36$)$ & 0.497 & 0.193 & 0.662 & 0.002 \\
\hline FFM of Legs (kg) & $0.99(0.76$ to 1.22$)$ & $1.11(0.80$ to 1.41$)$ & 0.947 & 0.341 & 0.561 & 0.003 \\
\hline FM of Arms (kg) & $-0.01(-0.09$ to 0.05$)$ & $0.06(-0.02$ to 0.15$)$ & 0.605 & 2.043 & 0.156 & 0.020 \\
\hline FM of Legs (kg) & $0.04(-0.27$ to 0.35$)$ & $0.18(-0.22$ to 0.58$)$ & 0.062 & 0.290 & 0.591 & 0.003 \\
\hline Fat of Trunk (\%) & $-0.57(-1.72$ to 0.57$)$ & $-0.43(-1.93$ to 1.06$)$ & 0.498 & 0.021 & 0.884 & 0.000 \\
\hline BF Android (\%) & $-1.45(-2.70$ to -0.20$)$ & 0.01 (-1.61 to 1.64$)$ & 0.845 & 1.860 & 0.176 & 0.018 \\
\hline BF Gynoid (\%) & $-1.39(-2.40$ to -0.37$)$ & $-0.32(-1.64$ to 0.98$)$ & 0.912 & 1.467 & 0.229 & 0.015 \\
\hline
\end{tabular}

$\mathrm{IC}=$ confidence interval; $\mathrm{a}=$ estimated mean adjusted by sex, age, Maturity Offset, and presence in class; $\mathrm{ES}=$ effect size; $\mathrm{BM}=$ body mass; DEXA= dual energy $\mathrm{x}$-ray absorptiometry; $\mathrm{BF}=$ body fat; $\mathrm{FM}=$ fat mass; $\mathrm{FFM}=$ fat free mass; $\mathrm{p}$-value $<0.05$.

Gender, age, and somatic maturation are important variables to be considered in the analysis of the effect of training on the body composition of children and adolescents, since girls tend to have greater body adiposity when compared to boys ${ }^{23}$, who tend to have higher muscle mass than girls, mainly considering hormonal issues ${ }^{24}$. It is also worth noting that age and somatic maturation should be considered in body composition analyzes, due to the nine months of follow-up, since the participants are children and adolescents and are in the process of growth and development which can modify body composition ${ }^{25}$, so the differences found are shown regardless of their growth and development. Likewise, the frequency of presence in class was included as an adjustment in the analyzes, since all young people who were reassessed after nine months, regardless of dropouts, or the minimum recommended attendance frequency (75\%), were included as an adjustment in the analyzes, evaluating the real effectiveness of the intervention ${ }^{26}$.

$\mathrm{Hui}^{12}$, in a study with adult participants, observed a decrease in BF in the group that performed Tai Chi Chuan practice after 12 weeks compared to the control group. Like Silva ${ }^{27}$ the study 
evaluated variables of physical fitness and body composition in children and adolescents between the ages of seven and sixteen and observed a reduction in $\mathrm{BF}$ in adolescents who practiced 12 weeks of judo (although it was not significant). Another study by Fukuda ${ }^{28}$ evaluated young judo athletes with an average of 5 years of training and a training volume of 7.8 hours per week during four weeks of preparatory competition training. The study identified a significant improvement in body composition in adolescents in a comparison between a period of pre- and post-training. In the present study, participants with no previous experience in the practice were submitted to two hours per week of intervention with Judo, so it is possible weekly training volume, as well as the absence of previous practice, was not sufficient to provide greater benefits.

Similarly to the evidence in the present study, Ito et al. ${ }^{9}$ observed, when body fat values were compared, no disparities between adolescents who practiced Judo and those who did not practice martial arts. Likewise in Milanese ${ }^{29}$ it was observed that in girls of eight to twelve years of age, volleyball or artistic gymnastics, and high-impact activities like judo, demonstrated a similar percentage of body fat for volleyball practitioners, very close to those of the intervention group of our study. The importance of the adjustment for presence in class is observed in the improvement in body composition, in addition to maintenance of body fat, particularly in the group that received the intervention, independent of attendance frequency and withdrawal from the program.

In spite of a lack of significant differences between the lean mass of the groups, it can be observed that there was a total increase, and per segment (arms and legs), in both analyzes. Like the present study, Ito ${ }^{9}$ compared adolescents practicing martial arts (Judo, Karate and Kung Fu) with the control group and also did not find significant differences, but the group who participated in fight activities presented higher values of total body mass.

Despite the relevance of the study, it is necessary to mention some limitations such as the lack of randomization of the sample, and the lack of control of food intake, (an important variable to be considered when analyzing body composition). Another aspect to be considered is the large difference between the number of boys and girls in the sample, making sex-stratified analysis impossible; a factor that should be considered in future studies. However, the strengths of this study include the analysis adjusted for confounding factors; such as sex, age, somatic maturation, and presence in class. Another factor to consider is the duration of the intervention performed in this study (nine months). An aspect which is especially important to mention when discussing this study is the population who performed the intervention (young people, participants in a social project).

In conclusion, after nine months of Judo intervention, maintenance of body adiposity in children and adolescents who performed judo training was observed as well as a slight increase in body adiposity in children and adolescents of the control group. Judo seems to be a good alternative of physical activity for body composition maintenance in children and adolescents. It is suggested that more studies use this model of intervention with the pediatric population, applying a longer time of intervention and addressing the limitations of this study.

\section{References}

1- Serdula MK, Ivery D, Coates RJ, Freedman DS, Williamson DF, Byers T. Do obese children become obese adults? A review of the literature. Prev Med. 1993. Mar;22(2):167-77.

2- Wang LY, Chyen D, Lee S, Lowry R. The association between body mass index in adolescence and obesity in adulthood. $\mathrm{J}$ Adolesc Health. 2008. May;42(5):512-8.

3- Whitlock G, Lewington S, Sherliker P, Clarke P, Emberson J, Halsey J, et al. Body-mass index and cause-specifi c mortality in 900000 adults: collaborative analyses of 57 prospective studies. Lancet. 2009. Mar 28;373(9669):1083-96.

4- Ara I, Vicente-Rodríguez G, Jimenez-Ramirez J, Dorado C, Serrano-Sanchez JA, Calbet JA. Regular participation in sports is associated with enhanced physical fitness and lower fat mass in prepubertal boys. Int J ObesRelatMetabDisord. 2004. Dec;28(12):1585-93.

5- American College of Sports Medicine. ACSM's Guidelines for exercise testing and prescription. 9th edition. Baltimore: Lippincott Williams \& Wilkins, 2014.

6- Borba-Pinheiro CJ, Carvalho MCGA, Drigo AJ, Silva NSL, Pernambuco CS, Figueiredo NMA, et al. Combining Adapted Judo Training and pharmacological treatment to improve Bone Mineral Density on postmenopausal women: A two years study. Arch Budo. 2013;9(2):93-99.

7- Prouteau S, Pelle A, Collomp K, Benhamou L, Courteix D. Bone Density in Elite Judoists and Effects of Weight Cycling on Bone Metabolic Balance. Med Sci Sports Exerc. 2006. Apr;38(4):694-700.

8- Hinrichs T, Chae EH, Lehmann R, Allolio B, Platen P. Bone Mineral Density in Athletes of Different Disciplines: a CrossSectional Study. Open Sports Sci J. 2010;3:129-33.

9- Ito IH, Mantovani AM, Agostinete RR, Costa Junior P, Zanuto EF, Christofaro DG, et al. Practice of martial arts and bone mineral density in adolescents of both sexes. Rev Paul Pediatr. 2016;34(2):210-15.

10- Nasri R, HassenZrour S, Rebai H, Neffeti F, Najjar MF, Bergaoui N, et al. Combat Sports Practice Favors Bone Mineral Density Among Adolescent Male Athletes. J CliniDensitom. 2015. Jan-Mar;18(1):54-9.

11- Andreoli A, Monteleone M, Van Loan M, Promenzio L, Tarantino U, De Lorenzo A. Effects of different sports on bone density and muscle mass in highly trained athletes. Med Sci Sports Exerc. 2001. Apr;33(4):507-11.

12- Hui SS, Xie YJ, Woo J, Kwok TC. Practicing Tai Chi had lower energy metabolism than walking but similar health benefits in terms of aerobic fitness, resting energy expenditure, body composition and self-perceived physical health. ComplementTher Med. 2016. Aug;27:43-50.

13- Freitas Jr IF, Bueno DR, Silva CB, Codogno JS, Conterato I, Fernandes RA, et al. Padronização de técnica antropométricas.1 ed. São Paulo: CulturaAcadêmica, 2008.

14- Mirwald RL, Baxter-Jones AD, Bailey DA, Beunen GP. An assessment of maturity from anthropometric measurements. MedSci Sports Exerc. 2002;34(4):689-694.

15- American College of Sports Medicine. Physical activity and Bone Health. MedSci Sport Exerc. 2004;36(1):1985-96. 
16- Gomes MSP, Morato MP, Duarte E, Almeida JJG. Ensino das lutas: dos princípios condicionais aos grupos situacionais.Movimento. 2010;16(2):207-27.

17- Brasil. Parâmetros Curriculares Nacionais. Educação Física: Ensino de quinta a oitava séries. Brasília, 1998.

18- Franchini E, Del Vecchio FB. Ensino de lutas: Reflexões e Propostas de Programas. Editora Scortecci, São Paulo, 2012

19- Borg G. Hassmén P, Lagerström M. Perceived exertion related to heart rate and blood lactate during arm and leg exercise. Eur J ApplPhysiolOccup Physiol. 1987;56(6):679-85.

20- Foster C. Monitoring training in athletes with reference to overtraining syndrome. Med Sci Sports Exerc. 1998. Jul;30(7):1164-8.

21- Franchini E, Del Vecchio FB, Matsushique KA, Artioli GG. Physiological Profiles of Elite Judo Athletes. Sports Med. 2011. Feb 1;41(2):147-66.

22- Tsang TW, Kohn M, Chow CM, Singh MF. A randomised placeboexercise controled trial of Kung Fu training for improvements in body composition in overweight/obese adolescents: the "Martial Fitness" study. J Sports Sci Med. 2009 Mar 1;8(1):97-106.

23- Pelegrini A, Silva DAS, Silva JMFL, Grigollo L, Petroski EL. Anthropometric indicators of obesity in the prediction of high body fat in adolescents. Rev Paul Pediatr. 2015;33(1):56-62

24- Malina RM, Penã Reyes ME, Eisenmann JC, Horta L, Rodrigues J, Miller R. Height, mass and skeletal maturity of elite Portuguese soccer players aged 11-16 years. J Sports Sci. 2000;18:685-93.

25- Jürimäe J. Growth, maturation and exercise - the year that was 2014. PediatrExerc Sci.2015;27:3-7.

26- Soares I, VazCarneiro A. Intention-to-treat analysis in clinical trials: Principles and practical importance. Rev Port Cardiol. 2002; 21(10):1191-8
27- Silva IO, Silva JL, Venâncio PEM, Teixeira CGO, Santana F. Effect of judo training on physical fitness related to health in children and teens. ColeçPesquiEducFís. 2012;11(2):81-88.

28- Fukuda DH, Stout JR, Kendall KL, Smith AE, Wray ME, Hetrick RP.The effects of tournament preparation on anthropometric and sport-specific performance measures in youth judo athletes.J Strength Cond Res. 2013. Feb;27(2):331-9.

29- Milanese C, Piscitelli F, Cavedon V, Zancanaro C. Effect of distinct impact loading sports on bodycomposition in pre-menarcheal girls. Sci Sports. 2014;29(1):10-19.

\section{Corresponding author}

*Bruna Thamyres Ciccotti Saraiva.

DepartmentofPhysicalEducation, Universidade Estadual Paulista. Rua Roberto Simonsen, $n^{\circ} 305$, Presidente Prudente, São Paulo, Brazil.

Email: brunatcsaraiva@gmail.com

Manuscript received on July 30, 2017

Manuscript accepted on September 16, 2017

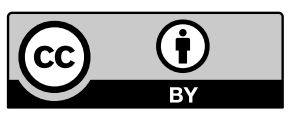

Motriz. The Journal of Physical Education. UNESP. Rio Claro, SP, Brazil - eISSN: 1980-6574 - under a license Creative Commons - Version 3.0 